\title{
INDEX AND ENGINEERING PROPERTIES OF SPENT WASH BLENDED SOILS- A COMPARATIVE STUDY
}

\author{
S. Siva Gowri Prasad ${ }^{1}$, V.K.Chakravarthi ${ }^{2}$ \\ ${ }^{1}$ Assistant Professor, ${ }^{2}$ Associate Professor, Department of Civil Engineering, GMR Institute of technology, AP, India, \\ gowriprasad.s@gmrit.org,chakravarthi.vk@gmrit.org
}

\begin{abstract}
In the present era of rapid industrialization and development of infrastructure projects, the natural resources are becoming scarce and hence their cost is increasing alarmingly. For an infrastructural project the soil consumption is very high and also specific soil is to be used for the requirements of its strength, durability etc. Locally available soil is the best option for these projects, if the suitable soil is not nearby it has a stringent effect on overall cost of project. Due to increase of demand for land in urban areas, soils which are weak and not suitable for foundations are to be effectively modified for construction of industries. Hence, there is a need to carryout research for an alternate material which is available in plenty and also gives desired strength upon modifications. There is a growing awareness allover the world about the extensive damage caused by the accumulated industrial wastes at various plants. This paper highlights various issues and scope for utilization of spent wash in engineering practice. This paper presents the results of index and engineering properties of blended soils. Studies are carried out by varying soil gradation, spent wash content under different curing time periods. For study two types of soils are taken and their properties are studied up on addition of $25 \%$ spent wash maintaining different curing periods of 2, 4 and 6 weeks. It was observed that spent wash is effective in reducing plasticity characteristics and increasing engineering properties namely, dry density and the unconfined strength of soil and reducing Optimum moisture content
\end{abstract}

Index Terms: Effluent, Tropical, spentwash, blended

\section{INTRODUCTION}

Industrialization plays a keen role for developing countries in uplifting nation's economy. However, industrialization on the other hand has also caused serious problems relating to environmental pollution. Therefore, efforts are to be made for controlling pollution arising out of the disposal of wastes by conversion of these unwanted wastes into utilizable raw materials for various beneficial uses. The present investigation is intended to study the effect on index and strength properties of two different soils with an effluent for different periods of curing. Muthukkumaan.K 2010 [3] investigated the Effect of Liquid Waste on the Index \& Engineering Properties of Cohesive Soils. Bujang B.K.Haut et al. 2005 [1] investigated the Effect of Chemical Admixtures on the Engineering Properties of Tropical Peat Soils. Suriyanarayanan.S et al. 2010 [5], Ratnap.Roy, Jagdish Prasad and A.P.Joshi, 2008 [4] studied the Characterization and possibilities of Reutilization of Soild Wastes from a Waste paper based Industry. Mohammadi A. K 2010 [2] studied the effect of paper mill sludge on chemical properties of acid soil. These studies concluded that the effect of effluent on the soil depends on the type of soil, nature of effluent and time of curing. In this study two soil samples and one effluent are selected.

\section{MATERIALS USED FOR STUDY:}

Two types of materials namely soil and spent wash, a waste product obtained from sugar plant are used for present study. For the purpose of study two types of sandy soils S-1 and S-2 with varying \% fines are collected from srikakulam, Andhra pradesh India. The samples of soil are collected from depth of 1 to $1.5 \mathrm{~m}$ from the ground level. The natural moisture contents of soil samples were nearly $28.1 \%$ and $15.28 \%$ respectively. Disturbed samples were collected and used for the test.

The spent wash used is an effluent of EID Parys sugar plant, Sankili, a place $15 \mathrm{~km}$ from Rajam, Andhra Pradesh, India. The sample was collected from equalization pond at a depth of $0.5 \mathrm{~m}$ from the surface of the pond and brought to the laboratory in tightly closed plastic cans. The effluents were filtered through filter paper to remove the suspended matter. The chemical constituents of spent wash are presented in Table: 1

Table-1: Chemical composition of Spent Wash

\begin{tabular}{|l|l|}
\hline Name & Present $(\%)$ \\
\hline Sucrose & $30-35 \%$ \\
\hline Reducing sugar & $10-15 \%$ \\
\hline
\end{tabular}




\begin{tabular}{|l|l|} 
Ash & $10-12 \%$ \\
\hline Total sugar \% dry solids & $55-60 \%$ \\
\hline Nitrogen & $0.15-0.25 \%$ \\
\hline Gums & $0.05-3.5 \%$ \\
\hline $\mathrm{CaO}$ & $1-1.5$ \\
\hline $\mathrm{SO} 4$ & $1.2-3.5$ \\
\hline $\mathrm{P} 2 \mathrm{O} 5$ & $0.25-0.3$ \\
\hline $\mathrm{PH}$ & $5.4-5.7$ \\
\hline
\end{tabular}

\section{EXPERIMENTAL STUDY:}

Laboratory Tests on spent wash treated soil samples are conducted for determining the index properties namely atterberg linits, engineering properties namely compaction characteristics i.e Optimum Moisture Content( OMC), Maximum Dry density( MDD) and unconfined compressive strength (UCS)of soil- spent wash effluent treated soil samples are determined by blending under different curing time varying from 2 to 6 weeks.. The blended soil samples are prepared by maintaining Spent wash at 0 and $25 \%$ of dry weight of soil sample. A comparison of result is carried out and discussed. The samples after mixing spent wash are allowed for curing. Testing is carried out as per the procedures described in BIS

Table-2: Index and engineering properties of soil samples ( $0 \%$ spent wash)

\begin{tabular}{|l|l|l|}
\hline $\begin{array}{c}\text { Solitescription } \\
\text { Parameter }\end{array}$ & Soil1( S1) & Soil2(S2) \\
\hline Gravel(\%) & 0 & 0 \\
\hline Sand(\%) & 91 & 96 \\
\hline $\begin{array}{l}\text { Fines(\%) } \\
\text { (Silt,Clay) }\end{array}$ & 9 & 4 \\
\hline Bulk Density & 1.862 & 1.777 \\
\hline Water Content & 28.1 & 15.9 \\
\hline Specific Gravity & 2.77 & 2.66 \\
\hline Liquid Limit & 55 & 59 \\
\hline MDD & 1.48 & 1.626 \\
\hline OMC & 25.2 & 19.5 \\
\hline IS Classification & Silty Sand & Silty Sand \\
\hline
\end{tabular}

\section{PRESENTATION OF RESULTS AND}

\section{DISCUSSION:}

Naturally available silty sand soil samples S-1 \& S-2 with varying fines were blended with spent wash at $25 \%$ of equivalent weight of soil and tests were conducted. The results of Index \& Engineering properties of soil samples, chemical properties of spent wash and Engineering properties of blended soil at different soaking durations (2,4 \& 6 weeks) were determined. The index and engineering properties of the soil samples S-1 and S-2 with 0\% spent wash were presented in Table-2. Variation of index and engineering properties of spent wash blended soils with curing time are presented in Fig. 1 to Fig.3.

\subsection{Presentation of Results for Index Properties of} Soil Blended with Spent Wash:

Effect of spent wash and curing time on index properties namely liquid limit, plastic limit and plasticity index is presented in fig. $1 \mathrm{a}, 1 \mathrm{~b}$ and $1 \mathrm{c}$.

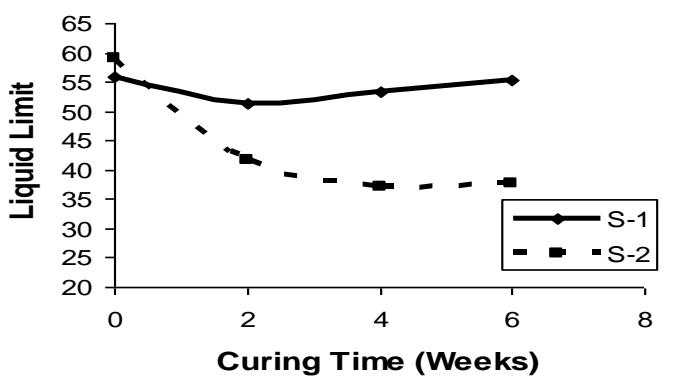

Fig -1a: Influence of curing time on Liquid Limit

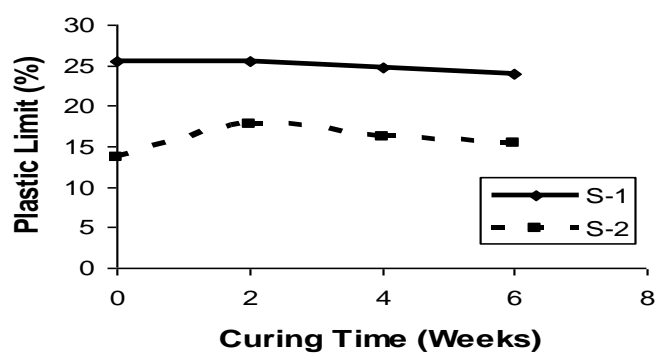

Fig -1b: Influence of curing time on Plastic Limit

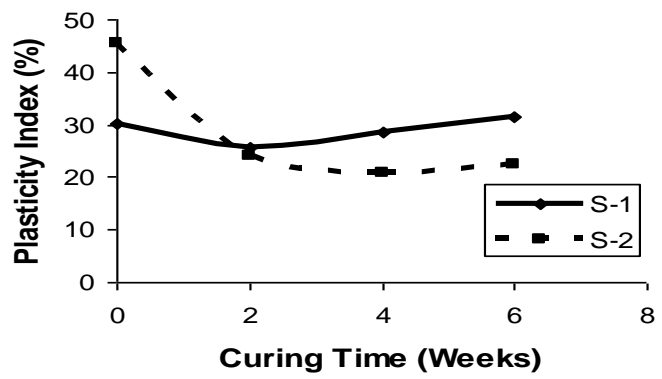

Fig -1c: Influence of curing time on Plasticity Index 
From the Fig-1a it is observed that Liquid limit is decreasing after 2 nd week curing period onwards for both the soils. This may be due to the percentage of water required for blended samples are gradually decreasing. Similar trend is also observed for plastic limit for soil sample S-1 as shown in Fig1b. In contrast for sample $\mathrm{S}-2$ there is an increase of plastic limit till 2nd week and later there is a decrease with spent wash curing time. This may be due to amount of fines present and change of state from semi solid - plastic state vis-à-vis volume. However as expected and observed from Fig-1c with increase of curing time there is a reduction in plasticity index. This is due to change in liquid limit and plastic limit with curing time and the plasticity index is numerical difference of liquid and plastic limits.

\subsection{Presentation of OMC-MDD Test Results:}

Optimum moisture content and maximum dry density tests were conducted on soil, spent wash mixtures at a fraction of $25 \%$ equivalent weight of soil and the results obtained were shown in fig- $2 \mathrm{a}$ and $2 \mathrm{~b}$.

\subsubsection{Variation of OMC with Spent Wash:}

From the fig-2a it was observed that the OMC was reduced gradually with increase in soaking duration. The behavior can be attributed due to filling up of voids in soil samples (S-1 \& $\mathrm{S}-2$ ) by spent wash. This has enhanced density of the soil under compactive effort resulting reduction in OMC. Spent wash was effective in reducing optimum moisture content of soil samples by $46.77 \%$ \& $20.83 \%$ respectively with the increase in soaking duration from 0 to 6 weeks.

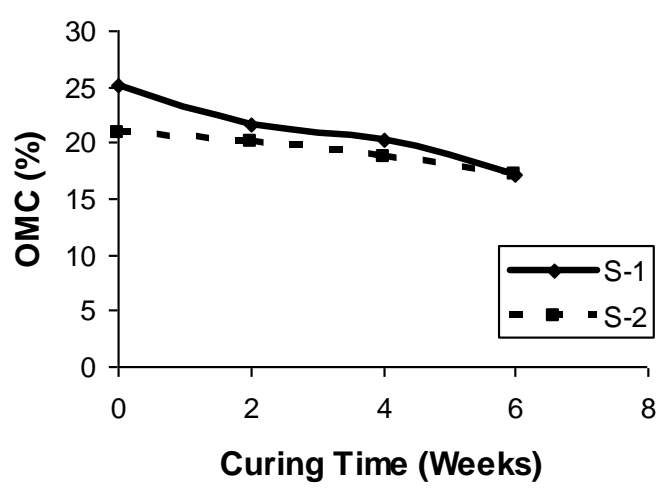

Fig -2a: Influence of curing time on OMC

\subsubsection{Variation of MDD With Spent Wash:}

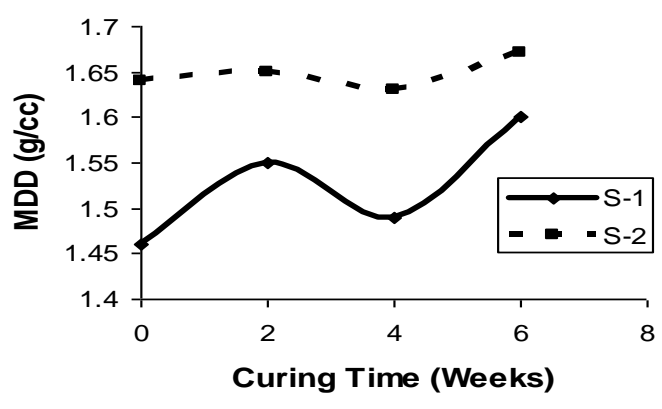

Fig -2b: Influence of curing time on MDD

From the fig- $2 b$ it was observed that the dry density has increased with curing time. However the increase is rapid for soil-1 and marginal for soil-2. At 4 weeks curing time for both soils the MDD has decreased and latter increased with curing time. This phenomenon can be attributed to the change in void ratio by addition of spent wash and lubrication effect with time for samples (S-1 \& S-2). Hence effect of compaction on the mixture increased density up to $7.5 \%$ and $2.09 \%$ on soil samples S-1 and S-2 respectively. There is raise in blended soil from $1.479 \mathrm{~g} / \mathrm{cc}$ at 0 weeks soaking duration to a maximum of $1.599 \mathrm{~g} / \mathrm{cc}$ at 6 weeks soaking duration.

\subsection{Variation of Unconfined Compressive Strength with Spent Wash:}

From the Fig-3 it was observed that the unconfined compressive strength is initially increased from 0 weeks to two weeks and latter decreased at 4 weeks soaking duration and then increased at 6 week duration. Since density has direct influence on strength and as mentioned in article 4.2, the variation of strength UCS is the replica of effect caused due to density change with curing time. The bonding forces in densified soil due to curing have an influence on strength.

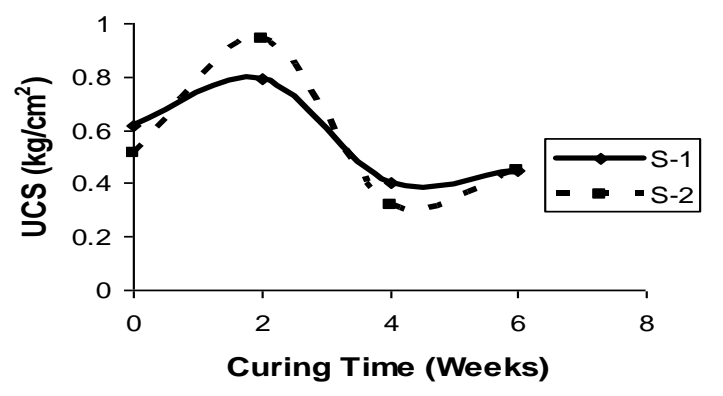

Fig -3: Influence of curing time on unconfined compressive strength 


\section{CONCLUSIONS}

From the tests conducted on two types of spent wash treated soil samples S-1, S-2 under different curing time for the variation of index and engineering properties the following conclusions are derived:

1. The spent wash effectively reduced Liquid Limit up to $6.90 \%$ for S-1 \& $55.43 \%$ for S-2.

2. The spent wash increased Plastic limit from $25.50 \%$ to $24.00 \%$ for $\mathrm{S}-1$ and from $13.705 \%$ to $15.33 \%$ for S-2.

3. The spent wash has reduced Plasticity index from $29.41 \%$ to $27.37 \%$ for $\mathrm{S}-1$ and from $45.065 \%$ to $22.48 \%$ for S-2.

4. The spent wash was effectively reduced OMC up to $46.77 \%$ for S-1 and $20.83 \%$ for S-2.

5. The spent wash was effectively increased MDD up to $7.5 \%$ for $\mathrm{S}-1$ and $2.09 \%$ for $\mathrm{S}-2$.

6. The spent wash was effectively increased the Unconfined compressive strength up to $27.4 \%$ for S1 and $84.3 \%$ for S-2.

\section{ACKNOWLEDGEMENTS}

The authors wishes to express their gratitude to Under Graduate students P.Laxmi Prasanna, K.G.Charan Kumar, M.V.Nikhil, Govindu, K.Harika, P.B.Srikanth for their support in the project work and to GMR institute of Technology-Rajam, AP, INDIA for the providing necessary facilities to carry out the project work.

\section{REFERENCES}

[1]. Bujang B.K.Haut, Shukri Maail and Thamer Ahmed, Mohamed 2005 "Effect of Chemical Admixtures on the Engineering Properties of Tropical Peat Soils" Department of Civil Engineering, Univesity Putra Malaysia, Serdang, Selangor, Malaysia.

[2]. Mohammadi A. Torkashvand, 2010 "The effect of paper mill sludge on chemical properties of acid soil", Islamic Azad University-Rasht branch, Rasht, Iran.

[3].Muthukkumaan.K. 2010 "Effect of Liquid Waste on the Index \& Engineering Properties of Cohesive Soils"Indian Geotechnical Jounral Vol.40, No.3, July

[4]. Ratnap.Roy, Jagdish Prasad and A.P.Joshi, 2008. "Changes in Soil properties due to irrigation with paper Industry Wastewater

[5]. Suriyanarayanan.S, A.S.Malilappa, D.Jayakumar, "Studies on the Characterization and possibilities of Reutilization of Soild Wastes from a Waste paper based Industry"

\section{BIOGRAPHIES}

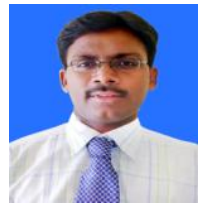

Mr SSG Prasad is currently associated with GMR Institute of Technology, Rajam, AP, India from 2010. Prior joining he has 7 years of experience in major Geotechnical engineering project works. .

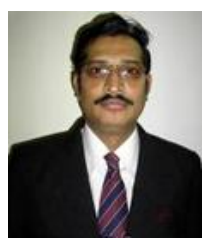

Mr. V.K. Chakravarthi, is Currently Associated with GMR Institute of Technology as Sr. Associate Professor in Department of Civil Engineering. He has a total experience of 18 years in Industry, Research and academics. 